importance. The 'dry' farming stations in Sholapur and Hagari have developed successful methods for soil and water conservation, and extension of this type of work is needed in other arid areas. As regards irrigation, many new projects are in hand or under contemplation, and it is estimated that the irrigated area will eventually be doubled. Various methods are being developed to minimize loss of water : for example, the use of concrete pipes, and the lining of canals and the protection of breakwaters and river banks against water erosion with various bitumen and asphalt materials. Greater economy in water would also be effected if it were paid for on a basis of supply, instead of at a fixed rate per acre of a particular crop as at present.

In the long run, however, the success of any project depends on the farming community itself. Dr. Mukherjee pointed out that much can be effected with the co-operation of the efficient farmer, and local interest can be stimulated by the setting-up of village committees and demonstration plots. Full use must be made of all existing knowledge, whether derived from the good farmer or the experimental station, if India's hopes of increased agricultural production are to be realized.

\section{RADIO DIRECTION-FINDING AND NAVIGATIONAL AIDS}

$\mathrm{T}$

HE use of direction-finding instruments for locating the source of radio signals is nearly as old as the technique of radio communication itself ; and a great deal of research has been done in Great Britain and elsewhere on the various methods available to-day for radio direction-finding. In some of these methods special receiving aerial arrangements are used to indicate the direction from which the signals are arriving from the distant transmitting station, while in other-systems the properties giving the finding of direction or position are incorporated in the principles of transmission employed. Two reports recently published under the auspices of the Department of Scientific and Industrial Research are of interest to contemporary scientific and technical workers on this subject.

The first of these, Radio Research Special Report No. 21*, contains translations, provided by the Admiralty, of nine papers written by German technical experts and not hitherto published. They describe some of the outstanding progress made in Germany in radio direction-finding during the Second World War. Seven of the papers were presented originally at an official German conference on navigational aids and allied problems in 1944, and two are later contributions.

Some of the papers contain the results of fundamental investigations designed to demonstrate the limitations in the accuracy of finding a position or direction imposed by wave propagation and other conditions. The relative merits of determining direction by the measurement of phase difference and time of arrival of the various component waves are discussed. Other papers describe the principles and experience obtained with new techniques demonstrating the influence of aerial spacing, a topic which

- Department of Scientiflc and Industrial Research. Radio Research Special Report No. 21 : Radio Direction-Finding and Navigational Alds ; some Reports on German Work issued in 1944-45. Pp. iv +92 . (London: H M.O. 1951) 38. 6d. net. has now become familiar to all those concerned with recent developments in the subject of radio directionfinding.

The second publication, Radio Research Special Report No. 22*, deals with the most important problem of selecting a satisfactory site for a radio direction-finding installation. Many radio directionfinders now available have a precision of better than one degree, and the accuracy of bearings is limited only by imperfections of the station sites, even when these are the best available in agricultural country of the type found in Great Britain. Much care is therefore necessary in the choice of sites, if full use is to be made of the potential accuracy of a direction-finder. Information on the effects of various imperfections of site, such as trees, buildings, hills and other sources of interference, is scattered throughout the literature of the subject. The report presents this information in a single publication.

The types of instrument considered are mainly those with loop or Adcock aerial-systems, and the frequency range covered, $100 \mathrm{kc} . / \mathrm{s} .-300 \mathrm{Mc} . / \mathrm{s}$. , is that in which such systems are commonly used. Poor sites in built-up areas or on ships are excluded, and the report deals only with normally acceptable sites. No precise definition of a suitable site is attempted, and the imperfections studied are those which would be undesirable within a quarter of a mile of the equipment and the effects of which might still be significant at a distance of one mile.

The report reviews the effects of natural and man-made objects, and, wherever possible, quantitative results of tests or operational experience are quoted. This cannot always be done owing to unpredictable variations between sites and sometimes between results obtained at the same site under varying conditions which cannot always be predicted. To demonstrate the theoretical aspects of the problems involved, the effect on accuracy of results of various simplified objects is discussed with particular reference to the effects of changes of frequency and the distance of the object from the receiver.

Special attention must be given to the calibration of direction-finders, particularly those with fixed Adcock aerial-systems. Allowance for site errors by means of corrections derived from observations on a local transmitter is possible in certain conditions, notably when errors are caused by objects close to the direction-finder: and the limitations on the choice of site imposed by the need for calibration to allow for instrumental errors are discussed. The main conclusions of the report are summarized in tables showing the minimum tolerable distances for different objects when it is desired to achieve specified accuracies. One table refers to good sites on which accuracies of $\frac{1}{2}^{\circ}$ at very high frequencies, and $2^{\circ}$ at lower frequencies, may be achieved. A second table refers to inferior sites where the corresponding figures are about $2^{\circ}$ and $5^{\circ}$.

Prepared as it was at the suggestion of the DirectionFinding Committee of the Radio Research Board of the Department of Scientific and Industrial Research, this report brings together the extensive experience of specialist workers in this field, and its publication should be of direct assistance to those concerned with the installation and use of radio direction-finding equipment.

* Lepartment of Scientific and Industrial Research. Radio Research Special Report No. 22: The Siting of Direction-Finding Stations. By W. Ross and F. Horner. Pp. iv +38. (London: H.M.S.O., 1952.) 18. 6 d. net. 